\title{
Los Sugar Daddies. Giros de la masculinidad hegemónica en tiempos posmodernos
}

\author{
The Sugar Daddies. Twists of Hegemonic Masculinity in \\ Postmodern Times
}

Noelia A. Meuli*

\section{Resumen}

En el contexto de los estudios de género y de masculinidades, se presenta una propuesta reflexiva sobre las relaciones de género y la dominación masculina en la actualidad analizando un tipo de relacionamiento especifico conocido como Daddy \& Babies Sugar ${ }^{1}$. Este artículo pretende brindar reflexiones sobre estas nuevas formas de vinculación entre hombres y mujeres desde lo que consideramos una concepción posmoderna, pero a su vez conservadora y androcéntrica.

Palabras claves: Dadys \& Babies Sugar -masculinidades hegemónicas- posmodernidadcomunicación virtual

\begin{abstract}
This type of virtual approach / virtual meeting has gained popularity especially in the upper social class sectors, with the United States, Europe and Latin America being the places with the most sugar babies in the world. During the analysis, it was possible to identify two current and stable key instances in the presentation, relationship and possible contractual conditions. After being identified, they necessarily need to be named. In this regard, I propose the concept of virtual approach (virtual approach) and virtual meeting (virtual meeting). The first term was designed to indicate a moment of rapprochement prior to a
\end{abstract}

\footnotetext{
*Licenciada en Ciencias de la Comunicación. (Universidad Nacional de Tucumán, Facultad de Filosofía y Letras). Tucumán, Argentina. Diplomada en Comunicación y Género (Defensoría del Publico -Civil, (CIM), (AFSCA) y (OEA). Investigadora en el área de área de género, masculinidades y paternidades (INVELEC- CONICET) y Doctoranda en Humanidades (Universidad Nacional de Tucumán, Facultad de Filosofía y Letras).

${ }^{1}$ En el proceso de indagación y orientado a los objetivos se tuvo en cuenta: solo las relaciones heterosexuales, el análisis de las páginas que se nombran en el desarrollo del presente y los testimonios de los/as participantes que han sido Dadys y Babys Sugar.
} 
Revista Punto Género N.16 Diciembre de 2021

ISSN 2735-7473 / 102- 118

meeting or agreement, while the second refers to more specific instances of the meeting, such as setting an appointment or starting a relationship.

Keywords: Dadys \& Babies Sugar- hegemonic masculinities - postmodernity- virtual communication

Fecha de recepción: Mayo 2021

Fecha de aprobación: Diciembre 2021

\section{Introducción}

La revisión de plataformas virtuales donde se llevan a cabo una modalidad especifica de relacionamiento denominada Dadys \& BabiesSugar ${ }^{2}$, que a primera vista podría arrojar conclusiones triviales, descubre un entramado mucho más complejo, que ha requerido el seguimiento e indagación sistemática de las páginas webs con mayor número de usuarios y usuarias en la actualidad. En términos generales un Dady Sugar se refiere a un hombre adinerado, laboralmente exitoso, que promedia entre los 30 y 70 años. Mientras que una Baby Sugar es una mujer mucho más joven que él, entre los 19 y 25 años, que lejos está de encontrarse en las mismas situaciones económicas. Un dady está dispuesto a cubrir las necesidades de su baby, principalmente económicas y puede solventar dependiendo de su status a una mujer o varias mujeres al mismo tiempo. En cuanto a ellas, son beneficiadas por este costeo, aunque no siempre una baby puede tener varios dadys, ya que los acuerdos tienden a exigir exclusividad para un solo hombre. Es importante destacar que esta relación se plantea en términos de contrato, se lleva a cabo de forma voluntaria, con acuerdo de las partes y en beneficio de ambas. Atravesando el análisis desde una perspectiva de género, en este artículo trataremos de explicar por qué existe este tipo de relación, la dinámica hombres-mujeres sostenida desde una socialización de género y los mecanismos sociales y culturales que habilitan y posibilitan este tipo de relacionamiento.

En mi lectura, los nombres con los que se ha denominado a los integrantes y la relación en si misma -provenientes del inglés- no es casual; si lo traducimos literalmente sería: padre (dad -dady), hija o bebé(baby) y sugar (azúcar). Brevemente, podemos percibir algunos sentidos en cuanto a la conjugación de los conceptos. Para destacar y de antemano, el de una relación que expresa jerarquía, necesidad y dependencia, como

'Los datos fundamentales extraídos en una primera instancia para indagar sobre el formato, características, modalidad y funcionamiento de las páginas webs, fueron tomados de tres plataformas en particular: sugarbook.com, richmeetbeautiful.com y seeking.com/es, por ser las más populares y con mayor cantidad de usurarios y usuarias. 
sería una relación tradicional entre un padre y un/a bebé. La palabra sugar es clave, ya que alude al sentido de lo dulce, la dulzura y demás connotaciones positivas en este contexto vincular. En esta relación, el significante de sugar conectada a dady y baby representa expectativas e ideales plasmados en dicho vinculo, que se espera sea primordialmente: cordial, agradable, exquisito, deleitoso, amable, cariñoso ylas expectativas se extiende al comportamiento de ambos, en el caso de la mujer viene en conexión con un aspecto aniñado y sumiso, en tanto en el hombre se asocia con el de ser generoso, dichoso y rico.

El análisis de las actitudes y comportamiento de los hombres y las mujeres participantes se llevó a cabo durante el segundo semestre del año 2019, siendo en la Argentina hasta el momento un tema novedoso del cual aún se conoce poco. En cuanto la construcción del marco teórico, incluye algunos lineamentos referentes a la Psicología puestos en diálogo con el campo de las Ciencias Sociales y las Ciencias de la Comunicación, desde una perspectiva de género.

Oriunda de países asiáticos, esta modalidad ha tomado rápida popularidad sobre todo en los sectores de clase social alta de lugares como E.E.U.U., Europa y en algunos países de América Latina, como México.

Durante el análisis se ha identificado dos instancias claves vigentes y estables en la presentación, relacionamiento y posibles condiciones contractuales. Luego de ser identificadas necesariamente precisan ser nombradas. Al respecto propongo el concepto de virtual approach (aproximación virtual) y virtual meeting (reunión virtual). El primer término fue pensado para señalar un momento de acercamiento previo a una reunión o acuerdo, mientras que el segundo hace referencia a instancias más concretas del encuentro, como fijar una cita o dar inicio a una relación.

Se sabe que en los últimos tiempos se ha intensificado la crítica hacia la estructura y organización de las relaciones de poder que integran los sistemas de género y hacia el interior de la construcción del género como categoría de análisis en sí mismo. Alejados de una propuesta biologicista comprendemos que el género integra una unidad de análisis social y subjetiva dentro de un contexto cultural e histórico determinado. Gayle Rubin (1975) utiliza el concepto de sexo-genero propuesto John Money (1955) quien explica la correspondencia directa entre los caracteres físicos, biológicos y genéticos que determina que una persona sea hombre o mujer. Sin embargo, para darle otro sentido desde un enfoque antropológico, el sistema también puede ser entendido como un objeto de estudio de interés cultural.

Este planteo se remonta a los años 80, en los comienzos de los estudios de género, devenidos principalmente del feminismo, el cual implica una postura política y filosófica que critica entre otras cosas, las asimetrías entre el hombre y la mujer. Más 
adelante, inspirado en los estudios académicos de la mujer y mujeres -en plural-, se inauguraron otros estudios como: los estudios de hombre (s) o estudios de masculinidad(es), también llamados Men's Studies. Los mismos surgieron como consecuencia del malestar, incomodidad y opresiones derivadas de las exigencias y los mandatos que implica ser varón, entre otras motivaciones.

Dentro del espectro teórico propuesto, la unidad de análisis del estudio de género no está basado en el universo que integra la feminidad ni en la masculinidad, sino por el contrario en las relaciones de género. Por eso, si quisiéramos preguntarnos ¿qué es ser varón en el presente? no solo tendríamos que revisar el concepto dentro de un contexto cultural e histórico, si no entrelazarlo con las relaciones de poder entabladas con el género femenino y fundamentalmente con sus pares varones, o por lo menos con quienes se sienten, reconocen y perciben como hombres. R. Connell propone:

Las relaciones de poder muestran las evidencias más visibles de las tendencias de crisis: un histórico colapso de la legitimidad del poder patriarcal, y un movimiento global por la emancipación de las mujeres. Esto es alimentado por una contradicción subyacente entre la desigualdad de mujeres y hombres, por un lado, y por las lógicas universalizantes de las estructuras del Estado moderno y de las relaciones del mercado, por otro (Connell,1995, p.9).

Frente a un aquí y ahora revolucionado, donde los roles y prácticas de género tradicionales se han modificado, resulta difícil o por lo menos cuestionable la presencia de los viejos $y$ ortodoxos modelos patriarcales representativos y propios del universo femenino y masculino. Sin negar que existan y aun sean predominantes el clásico binomio de un varón, poderoso, rico, fuerte, pudiente y exitoso, en contraste con una mujer, sumisa, dependiente y sensible, son características difíciles de sostener. Básicamente porque el presente histórico, capitalista, neoliberal, industrial y posmoderno, no acompaña. Entre otros cambios y de manera progresiva las mujeres se han vuelto mucho más independientes y los hombres debieron, de algún modo, flexibilizarse a experimentar masculinidades alternativas al modelo clásico. También cabe mencionar el impacto de los medios de comunicación, los cuales paulatinamente producen discursos y generan información sobre otros modelos disidentes de las estructuras clásicas del "macho". Los medios, independiente de su formato y soporte, son agentes socializadores y tienen un rol fundamental en la construcción y trasformación de la opinión pública, los imaginarios sociales y el relato subjetivo sobre nuestro presente social.

Estamos asistiendo un momento único de transición donde las formas tradicionales, androcéntricas y sexistas conviven con lo emergente, lo contra-hegemónico, lo alternativo, lo fluido y cambiante. Por lo tanto, es necesario dar a conocer lo mucho que esto afecta a nuestro proceso de investigación; se antepone a él la dificultad metodológica y la definición de un objeto de estudio que no para de mutar y diversificarse, sumando a 
que necesariamente debemos ejercer un recortar temporal deliberado pero justificado, que inevitablemente dejará fuera los sucesos más actuales, pero que de lo contrario sería imposible extraer conclusiones que nos permitan avanzar. Reconociendo un contexto particular que moviliza a muchos en Latinoamérica, como por ejemplo en la Argentina, visiblemente asistimos a la erosión de algunas ideas y certezas sobre las relaciones de género enraizadas, que implican, por ejemplo, revisar: los roles estereotipados sobre el sistema sexo-género y ampliar conceptos al respecto, la sexualidad, la identidad, expectativas, representaciones/demostraciones sociales, entre otras problemáticas afines al género.

También a nivel social/popular, se ha comenzado a desarmar otras ideas asociadas mayormente a las relaciones heterosexuales, como ser el amor romántico; dejando en evidencia las consecuencias y perjuicios que se ocultan bajo esta concepción del amor, que por lo general tiene buena reputación. Sin embargo, estas características aparentan ser prescindibles y hasta despreciadas para ser un Daddy o una Baby Sugar(D\&BS) terminan por convertirse en el núcleo y sostén de las mismas.

Como resultado de esta investigación, que no pretendemos sea exhaustiva y reconociendo ante todo las inabarcables posibilidades y variaciones en las relaciones entre D\&BS, nos aproximamos en base a algunos testimonios y el análisis crítico del discurso a evaluar cualitativamente el flujo y características de los mensajes e información presentes en estos portales de internet y los discursos que giran en torno a las experiencias personales. Uno de los primeros resultados a los cuales se arribó, fue que sí puede percibirse la ausencia de algunos rituales de cortejo y conquista tradicionales para ir directamente a una charla donde se especifican las pretensiones en pos de concordar una alianza. Allí se destaca primordialmente: a. solo existan pautas basadas en intereses económicos y ganancias personales, con la menor inversión de tiempo posible para hacer el trato y b. la posibilidad de tener relaciones sexuales o entablar un vínculo afectivo (que puede o no concretarse) no es requisito excluyente para el contrato.

Entre las tres páginas webs más relevantes analizadas, hallamos que las personas que se han vinculado a través de estas, comparten abiertamente su experiencia como D\&BS en la web, sobre todo a través de sus propios canales de YouTube, que fueron otra fuente principal de consulta, ya que allí, sin pudor las mujeres cuentan sus experiencias como babys. Se reconoce que en Argentina aún existen escasos datos, diversos tabúes y prejuicios/fetiches sobre esta modalidad de relacionamiento, y en la mayoría de los casos permanece asociado a la llamada prostitución VIP, tráfico de mujeres y otros hechos delictivos. En este sentido, consideramos fundamental la evaluación del contexto epistemológico desde donde se piensa el objeto de estudio y la posición de quien investiga, dejando a la vista que una investigación en profundidad y situada territorialmente daría indicadores más precisos. No es el propósito de este trabajo, que pretende ante todo ser exploratorio, descriptivo y aspira a brindar una panorámica 
Revista Punto Género N.16 Diciembre de 2021

ISSN 2735-7473 / 102- 118

introductoria al tema, contemplando variables de género desde una perspectiva teórica mixta.

\section{Páginas webs, interacción y dinámicas de relacionamiento}

A diferencia de otras páginas, la vinculación entre D\&BS deja en claro que no se trata de una búsqueda directa por encontrar el amor, ni tampoco consumar relaciones sexuales, aunque esto es una posibilidad latente y en algunos contratos necesaria e indispensable. Entre otras conclusiones, se percibe la gran concurrencia de mujeres que se exponen y/o participan como usuarias activasen estas páginas y no descarto que el atractivo para la población femenina, específicamente para las mujeres más jóvenes provenga justamente de la desmitificación y ausencia del amor romántico, de la alta expectativa de conseguir de manera rápida beneficios económicos y no tener la obligación de un encuentro sexual, ya que estas no necesariamente son piezas excluyentes para un padrinazgo exitoso. El acceso o contacto con una usuaria no garantiza que los mismos se efectúen y en el caso de llevarse a cabo, se puede acordar sin la obligación de un futuro contacto físico-en ocasiones existen contratos u ofertas de acuerdos millonarios de larga duración a distancia, sin que D\&BS deban conocerse personalmente, en otras las reglas se basan justamente en no tener relaciones sexuales-.

A priori para ellas, hipotetizamos lo siguiente: las características antes mencionadas brindan-en un mundo de hombres-, una cierta confianza y seguridad por parte de la mujer al momento de exponerse; ya que la idea del no contacto físico, trasmite una cierta noción de control sobre su propio cuerpo, el sujeto masculino y la dirección de la comunicación o el dialogo con él varón durante el acuerdo. Además, cabe señalar, la importancia de las posturas femenino-masculino previas al contrato, es decir, para un Daddy es atractivo y seductor que su bebé se mantenga distante y conserve un aura aniñada, virginal; esto la mayoría de las veces las vuelve más deseables, sin perder de vista que el juego se retroalimenta y es recíproco: es decir más atractivas ellas son, serán más pretendidas y por lo tanto podrán esperar, pedir y exigir mayores y mejores condiciones a un posible Daddy.

Por otra parte, no es de extrañar que estas páginas se autodefinan como portales de contratos amorosos con intereses previamente establecidos y no sitios de pornografía o prostitución. En esta dirección, existe una especie de réplica o continuidad en base a lo tradicional y misógino de la realidad. Se valora que las mujeres logran mantenerse pasivas, sumisas pero sensuales, mientras que ellos cumplen un rol activo y de cazador. Sin embargo, al igual que otras mujeres, juegan un rol pasivo adaptado a las necesidades del sujeto masculino. Como toda practica androcéntrica, los individuos se convierten en 
objetos para el uso y disfrute del varón, aunque eso no excluya la posible extracción de beneficios para sí mismas hasta por largos periodos de tiempo.

En principio, se podría afirmar que la libertad y autonomía que supone la construcción del contexto postmoderno en el cual vivimos, al mismo tiempo se destaca como sostén en la construcción ideológica de estas páginas. No obstante, desde nuestra perspectiva, las páginas operan de telón para difuminar una concreta, pero disimulada, imposición de poder y dominación masculina, que luego se manifiesta en un vínculo claramente hegemónico y androcéntrico, donde la importancia del capital monetario y el capital simbólico que de allí se desprende involucra un atractivo sistema de prestigio, ganancias y beneficios que ambos participantes -mujer/varón-, aprovechan y extraen de la relación para su propia conveniencia. Pero teniendo en cuenta dos aspectos claves: primero, la mujer corre con desventaja, principalmente económica y, segundo, la relaciones sostenida -por lo menos en lo analizado-, mediante atributos basados esencialmente en estereotipos heteronormados 0 , como menciona Judith Butler (2002),"performances y rol playing de género”.

En esta dirección, resulta interesante cómo la propuesta de Butler puede interpretarse (evitando que esto se lea como una postura reduccionista) como la existencia de un paralelismo en el sentido literal de la palabra, lo mismo que se pone en juego durante el proceso de conquista, ya que las performances, las actuaciones y posturas se materializan y son más simples de identificar al encontrarse exacerbadas y explicitas en los perfiles de quienes participan.

Dadas las características que posee la comunicación virtual, las construcciones ficticias y direccionadas no precisan ser sutiles. La imagen, la palabra, el dialogo, el intercambio de material fotográfico y audiovisual, los mensajes van mutando rápidamente a lo que se quiere ser o aparentar. Sin embargo, las normas y las reglas giran y/o terminan adaptándose al sistema tradicional de género para ambos, es decir: la exposición del género-como construcción sociocultural histórica- heteronormado es estratégica para conseguir lo que se quiere, prácticamente en su totalidad los/as participantes no escapan de los convenios tradicionales y opresivos de una organización social patriarcal.

\section{Roles y expectativas de género en revisión}

La dinámica en las páginas y testimonios analizados no dista mucho de la realidad, en mi planteo lo llamo de giros, pero también se podría añadir la idea de simulacros para salirse del sistema y la tradición de género, por parte de ambos participantes. Justifico: el hombre es quien manda y quien dispone de más dinero que la 
mujer, y ella si bien elige, no decide. Al contrario, acondiciona o planifica su futuro a sabiendas de la aceptación de una dependencia permanente o transitoria, sostenida a partir del contrato entre ambos porque supedita a que uno o más hombres la mantenga y así acceder a una vida de lujo, a una formación universitaria de prestigio, a una casa, entre otros bienes que no son siempre materiales, pero que ella no podría acceder por sí misma. Aquí se destaca una idea relacionada con lo que se espera, desea y quiere de un hombre o mujer. Hugo Huberman y Lucila Truffo (2012), se refieren a las expectativas de género y su mensura sociocultural:

Las expectativas de género son claves, ya que crean identidades, que, si bien no son estáticas, por el contrario, son permeables mantienen núcleos que aún están en revisión. Las expectativas e identidades son construcciones sociales que; marcan, connotan, definen, de acuerdo al género, pero también a la clase social, a la edad y a la etnia, y se van modificando a pasos agigantados, conforme pasa el tiempo (Huberman; Truffo, 2012, p.10).

Por eso es importante que cuando se produce un análisis, se tenga en cuenta la idiosincrasia y el contexto territorial de quienes allí habitan, de este modo se podrá encuadrar y comprender de manera más eficaz y cercana el modo en que, por ejemplo, las relaciones de género dentro de un sistema social que, si bien se caracteriza por ser androcéntrico y patriarcal, no deja de tener sus particularidades y adaptaciones según la zona geográfica. Así mismo, sucede cuando hablamos de poder y dominación, desde las grandes metrópolis hasta las comunidades más pequeñas cada una se organiza de manera particular. El poder tiene múltiples lenguajes, pero suele condensarse en prácticas que históricamente para la humanidad son constituyen su identidad y nos aglutinan: el amor, el dinero y las uniones afectivas, independiente del compromiso que allí exista. Al respecto Irene Meler (2017) advierte que "aun en las uniones informales, las diferencias de poder, saber y recursos existentes entre los amantes, no dejan de ejercer influencia y entramarse de modo íntimo con el enamoramiento, el deseo erótico y el apego que los une" (p.156). En este sentido la autora resalta:

No debemos perder de vista el nexo inextricable que une al deseo con las relaciones de poder, y estas relaciones tienen sólidas bases materiales. El acceso a los recursos económicos y al prestigio, ese capital simbólico intangible pero poderoso, se entraman en los modos en que los sujetos se desean, se alían, se apegan, etc. (Meler, 2017, p157).

En este momento, cabe preguntarnos: ¿las mujeres en su carácter de BS han invertido el orden de las cosas? En otras palabras, evidencian que el deseo de ser amada no es prioritario? Tal vez pueda haberse arrojado más claridad -por lo menos- en el plano discursivo que el deseo de ser queridas“(...) no se reduce al intercambio amoroso en sí 
Revista Punto Género N. 16 Diciembre de 2021

ISSN 2735-7473 / 102- 118

mismo, sino que se caracteriza por un anhelo de exclusividad, permanencia y reconocimiento" (Meler,2017,p.157).

Desde una perspectiva social-cultural, consideramos que la libertad de autonomía y autodeterminación manifestadas por D\&BS es en parte ilusoria, ya que de manera más o menos explícita ambos responden a normativas culturales patriarcales. Principalmente para las BS ya que este tipo de relación comienza por iniciativa y capital económico que posee el sujeto masculino, y tener el control puede volverse cuestionable en cuanto las relaciones empiezan y se terminan cuando el varón decide no invertir más en ellas y/o cambiarlas por otra BS. En concordancia, esta dinámica no sería posible si no existiese un contexto cultural que admite que los hombres tienen mejor remuneración económica, mejores trabajos y oportunidades -sobre todo cuando hablamos de cargos jerárquicos, corporativos y políticos. Algunos varones pueden sostener económicamente a una persona que ni siquiera conocen y por eso mismo, las mujeres son más propensas a acceder a estos acuerdos impulsadas, entre otras cosas, por la posibilidad de contar con bienes materiales y simbólicos a los que no podrían acceder por si mismas. En su mayoría, ellas mencionan explícitamente y sin tapujos que los DS y sus generosos padrinazgos son la oportunidad de acceder a lugares y beneficios imposibles de alcanzar por sus propios medios, que van desde la visita a un shopping, conocer algún país del mundo o estudiar en la universidad.

Aunque en los testimonios de las BS no mencionan concretamente el deseo de ser amadas, no lo descarto, por lo que encuentro interesante reflexionar mediante los aportes de Irene Meler.

El anhelo de ser amadas comparte hoy su importancia con ideales de autorrealización personal, en las jóvenes educadas de los sectores sociales medios. Pero no ha desaparecido, sino que sólo se ha moderado, y no encuentra una correspondencia semejante entre los hombres de esa misma generación, cuyo desarrollo de autonomía personal se enmarca en una larga tradición cultural y se hipertrofia en el contexto del individualismo postmoderno (Meler,2017,p.158).

En esta dirección, se pone en juego el deber ser y las expectativas tradicionalmente atribuidas al universo femenino y masculino. No es de extrañar que la propuesta por parte de los hombres esté orientada a cumplir con el mandato social hegemónico de ser protector, proveedor y procreador, un proyecto difícil de concretar en la realidad cotidiana. En cuanto a ellas, también se produce un traslado y acomodo hacia los roles tradicionales de ser básicamente sumisas y dependientes, pero no necesariamente pasivas, girando alrededor de la figura del padre/patriarca.

A pesar de que las páginas intentan escapar de lo convencional, por ejemplo: sortear los obstáculos que devienen del amor romántico, las subjetividades, vínculos y 
rituales inevitablemente son producciones sociales que demuestran su conexión cultural con esta idea, a pesar de que quiera evitarlo. Como ya lo he propuesto en otra oportunidad, la idea del amor romántico conlleva implicaciones determinantes en la conformación de las subjetividades en torno a las relaciones amorosas-afectivas. Dentro del amor romántico puede localizarse formas de violencia muy sutiles y disimuladas, bajo actitudes y comportamientos socialmente aceptados y por lo general valoradas como demostración de cuidado, afecto y protección, como las que un Daddy puede llevar a cabo. Esta idea encuadra, por ejemplo, en el concepto de micromachismos propuesta por Luis Bonino en el 2004

La desigual distribución del ejercicio del poder de dominio conduce a la asimetría relacional. La posición de género (femenino o masculino) es uno de los ejes cruciales por donde discurren estas desigualdades de poder, y la familia/pareja, uno de los ámbitos en que se manifiesta. Esto es así porque nuestra cultura patriarcal ha legitimado la creencia de que el masculino es el único género con derecho al poder autoafirmativo: ser varón supone tener el derecho a ser individuo pleno con todos sus derechos y derecho de ejercerlos (Bonino, 2004 $, \mathrm{s} / \mathrm{p})$.

Al respecto:

La condición sociocultural entreteje vínculos con la subjetividad, valiéndose de las representaciones sociales de género, que se constituyen como el principal recurso para plasmar modos de subjetivación enmarcados en cierto consenso social. Por lo tanto, el sistema sexo-género troquela definiciones simbólicas acerca del ser y deber ser de la feminidad y de la masculinidad, al generar normativas que deben ser cumplidas mediante discursos culturales, históricamente situados y políticamente construidos, que han perpetuado la dominación masculina (Bonino, $2004, s / p)$.

Ahora, teniendo en cuenta los aportes de Gabriela Córdoba y volviendo a la idea del contrato que de facto se da entre B\&D determinamos que existen otros contratos previos y subyacentes detectables, en los estudios de Luis Bonino dentro del contexto de los micromachismos, lo propone como; "la ecuación protección a cambio de obediencia del contrato de pareja tradicional refleja un importante aspecto de esta situación y demuestra la concepción del dominio masculino en la pareja" (Bonino, 2004 , s/p) 
Revista Punto Género N. 16 Diciembre de 2021

ISSN 2735-7473 / 102- 118

\subsection{Relaciones sobre dominio y poder}

En primera instancia se puede afirmar que las relaciones en donde intervienen estos dos factores (dominio y poder) son bastante complejas. Sin embargo, teniendo en cuenta las características del presente actual y desde una perspectiva de género podríamos concebir siguiendo la línea de Jessica Benjamin desarrollada en 1996 que la dominación es un proceso reciproco, dependiente y recursivo, que precisa y envuelve a quienes se someten al poder, así como la de quienes lo llevaran a cabo.

Los estudios realizados por la autora son esenciales, pues mediante una postura crítica y con enfoque de género revisa los grandes aportes de Freud sobre el poder y el psicoanálisis. Uno de sus objetivos está basado en entretejer el pensamiento analítico sobre el desarrollo individual, la diferencia entre géneros y la autoridad. Lo novedoso de su amplia obra deviene que su propuesta va más allá de criticar la postura freudiana clásica sobre el poder y la dominación por lo que explicita "Para desafiar la escisión sexual que impregna nuestra vida psíquica, cultural y social es necesario criticar no sólo la idealización del lado masculino, sino también la valorización reactiva de la feminidad”. (J. Benjamin 1988, p.20).

Notamos que efectivamente existen adaptaciones del modelo hegemónico camufladas y empáticas con la lucha feminista, solo para ser y permanecer siendo un patriarca dentro de un mundo posmoderno.

Una de las páginas webs más relevantes que almacena en su base de datos personas de todo el mundo se denomina Getting Arragement.com-Buscando un acuerdo$\mathrm{y}$, al igual que otras páginas de este tipo, indican que no se trata de plataformas destinadas al ejercicio de la prostitución o servicios de una mujer de compañía, también conocidas como Escorts, sino que proponen una manera no convencional y única de relacionamiento.

Para ingresar se debe realizar una suscripción, señalando la mayoría de edad y completar un perfil con datos personales que van desde el color de cabello hasta la etnia, y se complementa con un álbum de fotos personales. En el caso de ser mujer es fundamental indicar qué estilo de vida se lleva y cuál es el que desean tener. En esta página se categoriza en: negociable, minimalista, práctico, moderado o elevado. Asimismo, ellos deben indicar cuáles son sus ingresos anuales y las pretensiones sobre la futura relación: seria, ocasional, de corto o largo plazo, solo una salida para cenar, pasear, realizar un viaje juntos, ir de compras, pagar sus cuentas, costear su formación académica, etc.

En consecuencia, esto será el indicador referencial para que un S\&BS coincidan y puedan contactarse. Dicha dinámica a la que consideramos una relación de poder 
responde sin dudas, a un intercambio de intereses mediado por el dinero y resulta porque ambos se necesitan. La misma no existiría de no ser porque cada uno acepta su posición y desea lo que la otra persona posee o puede dar.

Brandon Wave, fundador de la página Seeking tiene 46 años y mantiene una relación con una mujer de 26. Explica para Vice en español, que al igual que todas las relaciones de pareja, él lleva un acuerdo con su BS basado en dar y recibir: él le paga por compañía para comprar ropa, cenar, viajar, etc. y ella por un estilo de vida que por sus propios medios no consigue: comprar zapatos y accesorios de lujo, viajes alrededor del mundo, educación universitaria de elite, etc.

Al igual que Brandon, los hombres que pueden convertirse en dadys son millonarios o mínimamente deben contar con ingresos elevados y esto es un requisito excluyente, la mayoría son empresarios o profesionales muy bien posicionados. Como mencionamos, a diferencia de otras páginas de encuentros o búsqueda de pareja, estas están orientadas a evidenciar los intereses y fines de manera clara, toda gira en términos económicos de ganancia, pero también de costo y pérdidas, ya sea de dinero, experiencias, estatus, prestigio y tiempo. En otra página icónica, como es Suggarboock.com, lleva como eslogan promocional promover una relación similar a un acuerdo de negocios bajo el slogan: Donde el romance se encuentra con las finanzas. Construye y negocia tus términos de relaciones.

Retomando con los aportes de Irene Meler, y en base a las propuestas teóricas de Connell, llevadas a cabo en 1995, la autora explica que la masculinidad hegemónica ocupa la cima de la pirámide de poder y prestigio y no por nada son ellos quienes sostienen la existencia concreta de estas páginas, la figura femenina aunque necesaria no deja de ser aleatoria, en el juego de la conquista. Aunque son imprescindibles también son reemplazables. Esto se explica porque el intercambio amoroso se efectúa mediante un contrato que va más allá de lo erótico, la seducción y el deseo en sí mismo. Mientras eso sucede se van construyendo lazos de estima, reconocimiento y otras pretensiones que se suponen se alcanzaran mediante dicho contrato. Si bien son muchos los factores que se pueden nombrar, se resumen en dos posiciones: por un lado la posición de una mujer económicamente insuficiente y por otro, la carencia o desgaste del estatus del hombre. Estas dos posturas al entrar en el marco del juego de roles son previamente asumidas, complementarias y mientras se mantengan garantizan el éxito de un contrato.

Cuando nos referimos a la masculinidad asociada al término de hegemonía, apuntamos toda practica que según Connell (1987) es "asumida por los hombres que legitima el patriarcado, la que garantiza la posición dominante de los hombres y la sumisión de las mujeres, no es de carácter fijo, no es la misma siempre y en todas partes, implica una masculinidad siempre disputable" (p.11). Como señala De Martino Bermúdez (2013) Connell "interpreta que las relaciones de género importan configuraciones de 
prácticas sociales específicamente de género. Para el caso de tales prácticas en términos de masculinidades, a partir del concepto gramsciano de hegemonía, el/la autor/a acuña el concepto de "masculinidad hegemónica" (p.286). Por lo tanto "la configuración de práctica genérica que encarna la respuesta corrientemente aceptada al problema de la legitimidad del patriarcado, la que garantiza -o se toma para garantizar- la posición dominante de los hombres y la subordinación de las mujeres" (Connell, 1995, p. 39).

Es importante señalar que no todos los hombres son capaces de llevar adelante este tipo de masculinidad hegemónica y de hecho representan la minoría. Los mismo suelen agruparse y formar espacios restringidos para ellos y sus pares, espacios donde pueden satisfacer sus necesidades patriarcales -percibidas como sus derechos- sin tapujos ni restricciones, aunque eso signifique pagar con dinero por ello. Sentirse útil y estimado es vital para su ego y reafirmación como un verdadero varón. Este comportamiento es claramente gratificante e importante porque, entre otras características: tienen a quien proteger, quien dependa de él, lo admire, lo respete, etc. Cuidar y contener a alguien más débil le da control y posiblemente le reconforta saber que podrá afirmar su virilidad luciendo antes sus pares y toda la sociedad no solo la compañía de una mujer hermosa, mucho más joven que él, deseable y dispuesta a servirlo, sino la ejecución de sus deberes viriles contribuyentes a subir o bajar su "nivel de hombría".

Desde nuestra postura consideramos que estos portales son un espacio legitimador de discursos y prácticas sexistas camufladas bajo la amabilidad y el acuerdo mutuo. En la descripción de los perfiles de los/as usuarios/as, sumado al contenido informativo de las páginas se filtran lineamientos concomitantes a las concepciones de masculinidad hegemónica patriarcal, de manera persuasiva, disimulada y silenciosa que se impone mediante la jerarquía masculina, bajo el lema hagamos o tenemos un trato. Por lo tanto, resulta clave interrogarnos sobre las elecciones: ¿Se trata de un contrato o de una ilusión de acuerdo?

\subsection{2. ¿Son ellas las que eligen o son ellas las elegidas por ellos?}

Sin dudas este es uno que se mantuvo latente en el momento de analizar las páginas webs y preguntarnos al mismo tiempo sobre el rol de la mujer en particular. Considerando los datos disponibles, analizamos sin intención de minimizar las complejidades de cada caso, que si bien ellos son los que se ofrecen, también son quienes ordenan los modos en el que se dará el acuerdo básicamente porque disponen del dinero, factor primordial que motoriza y mantiene la relación, dejando a priori a la mujer en una posición de inferioridad. Encontramos que ellas son necesarias para complementar su condición de poderío e intensificar su liderazgo y ratificación del carácter masculino hegemónico. Por más que se benefician y el acuerdo puede resultar más cómodo y fructífero para ellas, no dejan de ser una pieza accesoria y descartable o remplazable en el tiempo. 
Las prácticas que originan y refuerzan las asimetrías entre varones y mujeres no siempre se muestran violentas o extremas. A nuestro criterio, estas páginas son una evidencia y en un intento por re-avivar el planteo nos preguntamos: ¿sería válido pensar que ellos pagan para acceder, pertenecer y permanecer a una masculinidad hegemónica?; ¿La masculinidad social funciona como un club de "machos posmodernos" y en los sectores más altos, en los que se reproduce las masculinidades hegemónicas, se trata de espacios exclusivos y excluyentes?

Esta comparación se acerca bastante a las características de nuestro objeto de estudio ya que los miembros y usuarios que integran la denominada comunidad de D\&BS, están organizados por niveles, cuanto mayor son los ingresos económicos anuales del sujeto masculino el participante estará mejor calificado, y por lo tanto será capaz de obtener beneficios extras con las candidatas. Particularmente en Seeking.com, el público de varones esta segmentado mediante un orden ascendente. Las categorías de pertenencia se dividen en: Diamonsmembers, Premium members, Backgraundmembers. ${ }^{3}$

En este sentido, notamos cómo las relaciones de poder no solo son verticales (varón-mujer) sino también horizontales (varón-varón). Sobre las relaciones de poder, para Gabriela Córdoba (2015) "la importancia de las pautas y conductas que a lo largo del tiempo modelan los deseos y reglamentan el modo en que los sujetos deben pensar, actuar, relacionarse con su cuerpo y con sus sentimientos. Y la lógica hegemónica es masculina, y se encuadra en un paradigma androcéntrico" (p.6).

Teniendo en cuenta esto y los posicionamientos masculinos que han sido valorados para este escrito, es posible volver a pensar sobre las relaciones de poder que se ponen en juego durante los arreglos contractuales. En este sentido, reivindicamos la teoría feminista en cuanto impulsora y resistente a las relaciones asimétricas entre hombres y mujeres, pero añadimos la propuesta de Jessica Benjamin para problematizar algunos fundamentos interiorizados sobre las asimetrías femenino-masculino.

Una tendencia principal del feminismo ha construido el problema de la dominación como el drama de la vulnerabilidad femenina victimizada por la agresión masculina. Incluso los pensadores feministas más perspicaces a menudo retroceden ante el análisis de la sumisión, por miedo a que, al admitir la participación de la mujer en la relación de dominio, la responsabilidad pase de los hombres a las mujeres, y la victoria moral de las mujeres, a los hombres. Más, en general, ésta ha sido una debilidad de la política radical: idealizar a los oprimidos, como si la política y la cultura de éstos nunca hubieran sido alcanzadas por el sistema de dominación, como si las personas no participaran en su propia

\footnotetext{
${ }^{3}$ Para incrementar el número de interesadas/os las páginas de D\&BS permiten mediante un abono obtener un certificado oficial de membresía y su verificación de la cuenta, es decir se garantiza que la identidad de esa persona es real, al igual que sus ingresos.
} 
sumisión. Reducir la dominación a una relación simple de agente y paciente equivale a reemplazar el análisis por la indignación moral. Además, esa simplificación reproduce la estructura de la polaridad de los géneros, bajo la apariencia de atacarla. (Córdoba, 2015, p.20)

Entre lo viejo, lo nuevo, adaptaciones y contradicciones, resulta fundamental comprender que el estudio desde una perspectiva de género suscita un trabajo multidisciplinario y colaborativo. Realizar un abordaje crítico de estas páginas ha significado volver a cuestionarnos sobre las dificultades que implica un cambio cultural, los avatares de las trasformaciones, y la necesidad de flexibilizar las posturas extremistas o totalitarias sobre los complejos y heterogéneos modos de relacionamiento entre varones y mujeres, así como criticar los clichés y tabúes que giran en torno a esta discusión.

\section{A modo de conclusión}

Uno de los propósitos de este estudio fue comprender las relaciones basadas en acuerdos denominadas B\&D Sugar y a su vez desde una perspectiva de género desentramar qué motivos y de qué manera los mismos funcionan y son posibles. Si bien, los contratos son voluntarios, conscientes, libres y quienes participan obtienen un beneficio (lo que no sugiere ser un conflicto), se convierte en un problema de investigación cuando se lo analiza desde un paradigma de género. Aquí, encontramos que estas páginas webs podrían significar en la actualidad un nicho, un espacio en concreto, donde entablar un vínculo que lejos de empoderar y/o descolocar a los hombres y las mujeres de su rol tradicional de género produce un espejismo de equidad, ya que la estructura basal y el intercambio de intereses se ordenan según los roles y expectativas de género (femenino-masculino) heteronormado. Asimismo, los contratos son una forma de menguar el hecho de admitir las desigualdades entre ambos, que en este caso se destaca principalmente: el poderío social y económico obtenido por los hombres como un valor agregado a ser varones por sobre las mujeres, quienes solo cuentan con el capital de su propio cuerpo, las capacidades de compañía y cuidado solo por ser mujeres.

En estas relaciones la estructura social patriarcal se reproduce con claridad, aunque de forma más sutil. Podríamos decir que no hay "ganadores/as y perdedores/as", primero porque existen regulaciones contractuales y segundo porque se mantiene un vínculo de poder/dependencia donde cada una de las partes no escapa de su mandato/estereotipo limitante de género impuesto socio-culturalmente (romper con esto sería no poder acordar una relación), sin embargo, esto no quita que el poder del hombre prevalezca, por ser quien dispone del capital monetario y, por ende, capaz de inaugurar los acuerdos. 
Por otra parte, notamos que frente a una realidad que cuestiona las asimetrías de género, muchos hombres se han quedado sin saber cómo poner en práctica su masculinidad tradicionalmente aprendida, se les ha quitado por decirlo de algún modo, los pilares que constituían ser un verdadero varón, sintéticamente por dos motivos generales. Primero: son muy pocos aquellos que tienen acceso a un estatus socioeconómico privilegiado y segundo porque las mujeres han producido rupturas sobre el modelo clásico de un hombre proveedor, dedicado a protegerlas y cuidarlas. En general se han independizado y nos encontramos en un momento paradigmático donde las formas convencionales de relacionamiento están puestas bajo la lupa.

Asimismo, es importante destacar, que los movimientos sobre los patrones sexistas y androcéntricos también han descolocado el rol tradicional de la mujer, su postura frente el mundo, las expectativas acerca de ella misma y las puestas sobre una posible pareja, candidato o relación amorosa-afectiva. Será necesario reconocer que hay mujeres que gustan, eligen, desean o solo ocupan en su imaginario la feminidad en términos de sumisión, y dependencia. Aquí, probablemente ha de producirse el mismo vacío que en los hombres, sumado a una realidad laboral y económica que no las favorece.

Por último, con respecto a los factores comunicacionales de estas páginas, consideramos que las mismas son una invención creativa y discursivamente atractiva para perpetuar los roles asimétricos, dependientes y restrictivos que la sociedad marca para cada género, pero de manera aggiornada a un contexto postmoderno. Aunque los contratos se jactan de ser beneficiosos para ambos participantes, no dejan de ser una demostración de una lógica androcéntrica y patriarcal que aún permanece fuertemente arraigada a nuestra cultura y atraviesa a hombres y mujeres de manera represiva y condiciona sus comportamientos.

\section{Bibliografía:}

Benjamin, Jessica(1988): The Bonds of Love, psychoanalysis, feminism, and the problem of domination. United States of America. Patheon books: New York.

Bonino Méndez, Luis (2004): "Los micromachismos" en La Cibeles, Vol.2, s/p.

Butler, Judith (2002): Cuerpos que importan. Sobre los limites materiales y discursivos del sexo. Barcelona: Paidós. 
Revista Punto Género N. 16 Diciembre de 2021

ISSN 2735-7473 / 102- 118

Connell, Raewyn (1987):Gender and Power: Society, the Person and Sexual Politics. Cambridge: PolityPress.

Connell, Raewyn (1995):Masculinities. Cambridge: PolityPress.

Córdoba, María Gabriela (2015):La construcción hegemónica masculina y sus efectos en el ejercicio de la sexualidad y los vínculos de pareja en varones tucumanos. [Acta de Congreso]. XI Jornadas de sociología de la UBA. Buenos Aires, Argentina. Disponible en: https://cdsa.aacademica.org/000-061/838

De Martino Bermúdez, Mónica(2013): “Connell y el concepto de masculinidades hegemónicas: masculinidades hegemónicas: notas críticas desde la obra de notas críticas desde la obra de Pierre Bourdieu Pierre Bourdieu" en Estudios Feministas, Vol.21, No.1, p.283-300.

Huberman, Hugo \&Trufo, Lucila (2012): Masculinidades plurales: reflexionar en clave de géneros. Programa Naciones Unidas para el Desarrollo-PNUD. Trama.

Meler, Irene (2017) : Relaciones amorosas en occidente contemporáneo: encuentros y desencuentros entre géneros. En Meler, I.(comp). Psicoanálisis y género. Escritos sobre el amor, el trabajo, la sexualidad y la violencia. Buenos Aires: Paidós.

Money, John. J.J.C. Hampson \&J.I. Hampson, (1955): "Hermafroditism: recommendations concerning assignment of sex, change of sex, and psychological management", Bulletin of the Johns Hopkins Hospital, Vol. 97, p. 284-300.

Rubin, Gayle (1975): El tráfico de mujeres. Notas sobre la "economía política" del sexo. Monthly Review Press. 